\title{
Electronic structure of tris(8-hydroxyquinoline) aluminum thin films in the pristine and reduced states
}

\author{
N. Johansson, T. Osada, Sven Stafström, William R. Salaneck, V. Parente, D. A. dos Santos, \\ Xavier Crispin and J. L. Bredas
}

\section{Linköping University Post Print}

\begin{abstract}
N.B.: When citing this work, cite the original article.
\end{abstract}
Original Publication:

N. Johansson, T. Osada, Sven Stafström, William R. Salaneck, V. Parente, D. A. dos Santos, Xavier Crispin and J. L. Bredas, Electronic structure of tris(8-hydroxyquinoline) aluminum thin films in the pristine and reduced states, 1999, Journal of Chemical Physics, (111), 5, 2157-2163.

http://dx.doi.org/10.1063/1.479486

Copyright: American Institute of Physics (AIP) http://www.aip.org/

Postprint available at: Linköping University Electronic Press http://urn.kb.se/resolve?urn=urn:nbn:se:liu:diva-81302 


\section{AIP $\begin{gathered}\text { molowanat } \\ \text { chemical Physics }\end{gathered}$}

Electronic structure of tris(8-hydroxyquinoline) aluminum thin films in the pristine and reduced states

N. Johansson, T. Osada, S. Stafström, W. R. Salaneck, V. Parente et al.

Citation: J. Chem. Phys. 111, 2157 (1999); doi: 10.1063/1.479486

View online: http://dx.doi.org/10.1063/1.479486

View Table of Contents: http://jcp.aip.org/resource/1/JCPSA6/v111/i5

Published by the American Institute of Physics.

Additional information on J. Chem. Phys.

Journal Homepage: http://jcp.aip.org/

Journal Information: http://jcp.aip.org/about/about_the_journal

Top downloads: http://jcp.aip.org/features/most_downloaded

Information for Authors: http://jcp.aip.org/authors

\section{ADVERTISEMENT}

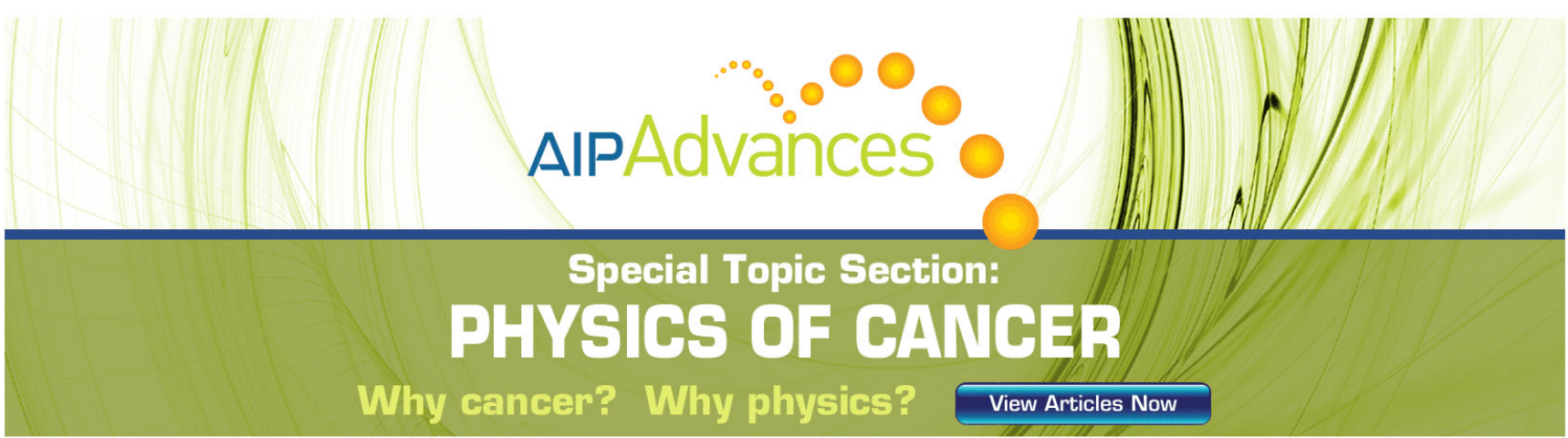




\title{
Electronic structure of tris(8-hydroxyquinoline) aluminum thin films in the pristine and reduced states
}

\author{
N. Johansson, T. Osada, ${ }^{\text {a) }}$ S. Stafström, and W. R. Salaneck \\ Department of Physics (IFM), Linköping University, S-581 83 Linköping, Sweden \\ V. Parente, D. A. dos Santos, X. Crispin, and J. L. Brédas \\ Service de Chimie des Matériaux Nouveaux, Centre de Recherche en Electronique et Photonique \\ Moléculaires, Université de Mons-Hainaut, Place du Parc 20, B-7000 Mons, Belgium
}

(Received 16 March 1999; accepted 28 April 1999)

\begin{abstract}
The electronic structure of tris(8-hydroxyquinoline) aluminum $\left(\mathrm{Alq}_{3}\right)$ has been studied in the pristine molecular solid state as well as upon interaction (doping) with potassium and lithium. We discuss the results of a joint theoretical and experimental investigation, based on a combination of x-ray and ultraviolet photoelectron spectroscopies with quantum-chemical calculations at the density functional theory level. Upon doping, each electron transferred from an alkali metal atom is stored on one of the three ligands of the $\mathrm{Alq}_{3}$ molecule, resulting in a new spectral feature (peak) in the valence band that evolves uniformly when going from a doping level of one to three metal atoms per $\mathrm{Alq}_{3}$ molecule. (C) 1999 American Institute of Physics. [S0021-9606(99)50628-4]
\end{abstract}

\section{INTRODUCTION}

Since the first reports of efficient electroluminescence from an organic thin film device using the metal chelate tris(8-hydroxyquinoline) aluminum $\left(\mathrm{Alq}_{3}\right)$ as the emissive layer material, ${ }^{1}$ research and development on organic light emitting diodes (OLED) have led to the point that products are entering the market place. The chemical structure of the $\mathrm{Alq}_{3}$ molecule is given in Fig. 1. Thin films of $\mathrm{Alq}_{3}$ are among the most efficient electroluminescent molecular films known to date, exhibiting excellent chemical stability and high luminescence efficiencies. ${ }^{2-5}$ In addition, thin films of $\mathrm{Alq}_{3}$ have been studied as electron transport layers (or hole blocking layers), in order to improve the performance of multilayer devices where the light emitting material is a conjugated polymer. ${ }^{2,6}$

Previously, we have applied a combined experimental and theoretical approach to studies of the interaction of sodium, potassium, or rubidium atoms with ultraclean surfaces of thin films of polyparaphenylenevinylene (denoted PPV), substituted PPV's, related model molecular solid systems, as well as polythiophene derivatives. ${ }^{7-12}$ In most cases, it was found that the alkali metal atoms donate electrons to the $\pi$-electron system leading eventually to the formation of self-localized states such as polarons or bipolarons. In the case of the interaction of rubidium atoms with PPV, the transition from polaron states to bipolaron states was observed. ${ }^{13}$ The formation of polarons results in the generation of two new energy levels within the original forbidden energy gap; however, only the upper polaron level is clearly resolved from the remainder of the valence band in the experimental data. The generation of bipolarons, on the other hand, results in the appearance of two resolvable in-gap peaks.

In this contribution, we present the results of a joint

a) Permanent address: Sumitomo Chemical Co. Ltd., Tsukuba Research Laboratory, Kitahara 6, Tsukuba 300-32, Japan. experimental and theoretical study of the interaction of lithium or potassium atoms with $\mathrm{Alq}_{3}$ molecules in molecular thin films. Our goal is to contribute to the general understanding of the nature of the interaction of metal atoms with organic materials, as well as to clarify the nature of the negative charge storage states in the $\mathrm{Alq}_{3}$ molecule. The experimental part consists of a combination of ultraviolet and x-ray photoelectron spectroscopies, UPS and XPS. UPS is used to study the valence electron energy distribution and changes therein induced by charge transfer doping, while XPS is used to address sample surface cleanliness and the degree of charge transfer. The changes in both the density-of-valencestates (DOVS), and the magnitude of charge transfer can be analyzed with help from the results of quantum-chemical calculations. ${ }^{14}$ Here, calculations were performed at the density functional theory (DFT) level, ${ }^{15}$ in which estimates of electron correlation effects are explicitly included. The DFT approach has been successfully used in earlier descriptions of the interactions of metal atoms with conjugated molecules. ${ }^{16-20}$

\section{EXPERIMENT}

Thin films of $\mathrm{Alq}_{3}$ were prepared by thermal evaporation from a Knudsen cell onto optically flat $\mathrm{Si}(110)$ substrates. XPS and UPS were carried out in Linköping in an instrument of our own design and construction, with a base pressure of $10^{-10}$ mbar. Unfiltered $\operatorname{Mg}\left(K \alpha_{1} \alpha_{2}\right)$ radiation $(1253.6 \mathrm{eV})$ was used for XPS, while ultraviolet He I $(21.2 \mathrm{eV}$ photon energy) radiation was obtained from a differentially pumped helium resonance lamp. The resolution of the electron energy analyzer was set to $0.2 \mathrm{eV}$ for XPS, such that the full-width at half-maximum for the $\mathrm{Au} 4 f_{7 / 2}$ line is $0.9 \mathrm{eV}$. For UPS, the analyzer resolution was set to $0.1 \mathrm{eV}$. Energy calibration was performed on gold, with the Au $4 f_{7 / 2}$ line at $83.8 \mathrm{eV}$ below the Fermi level in XPS, and using the Fermi level of $\mathrm{Au}$ at $0 \mathrm{eV}$ in UPS. The work function of the samples, both 


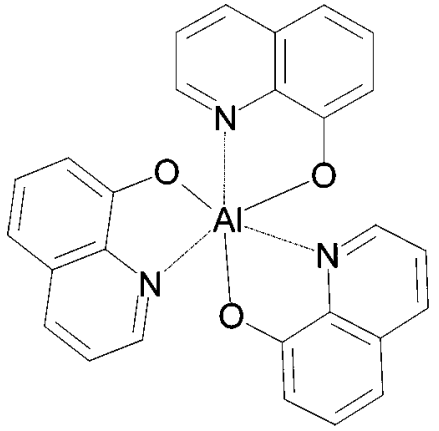

FIG. 1. Chemical structure of tris(8-hydroxyquinoline) aluminum ( $\left.\mathrm{Alq}_{3}\right)$.

in the pristine state and following the deposition of metal atoms, was estimated from the cut-off of the secondary electron distribution in the UPS spectra. ${ }^{21}$

Lithium or potassium atoms were deposited in situ from SAES ${ }^{\circledR}$ getter sources. The deposition rate was controlled, through precalibrated steps, to essentially monolayer equivalent doses. Deposition steps were monitored with XPS. In the case of potassium atoms, the atomic concentrations were estimated from the intensity ratio of the $\mathrm{K}(2 p)$ intensity to the $\mathrm{C}(1 s)$ intensity. On the other hand, the very low value of the cross section of the Li $1 s$ core level does not allow the determination of the lithium concentrations using XPS; instead, the lithium metal concentrations were estimated by comparison with the potassium concentration at the corresponding deposition steps (same current and same total time of metal deposition); the changes in the UPS spectra at the estimated similar stages of metal coverage were consistent with these estimates. The changes in the electronic structure of $\mathrm{Alq}_{3}$ were studied up to a concentration of three metal atoms per $\mathrm{Alq}_{3}$ molecule. Although all of the core level spectra were recorded, only the evolution of the nitrogen $1 s$ core levels is shown below, since only small changes were observed in the other core levels.

\section{THEORETICAL METHODOLOGY}

The $\mathrm{Alq}_{3}$ molecule and its complex with one $\mathrm{K}$ atom were investigated theoretically using DFT calculations performed with the DMol software. ${ }^{22,23}$ The geometrical structures of both the single molecule, and of its complex with one potassium atom, were estimated by full molecular geometry optimization at the local spin density approximation (LSDA) of DFT, using the Vosko-Wilk-Nusair (VWN) exchange-correlation potential, ${ }^{24}$ with a DNP (double numerical+polarization) basis set and a fine grid. ${ }^{25}$ The LSDA approximation provides reliable estimates of molecular geometries for conjugated oligomers interacting with metal atoms. ${ }^{19}$ Using the LSDA-optimized geometrical structures as input, the electronic structure (energy eigenstates and charge population analysis) was refined using the gradient-corrected Becke-Lee-Yang-Parr (BLYP) exchange-correlation functional. ${ }^{26,27}$

The UPS spectra, both of the pristine $\mathrm{Alq}_{3}$ molecule as well as of the molecule interacting with potassium, were simulated from the DFT eigenenergies using the generalized transition state (GTS) method. ${ }^{28,29}$ We recall that at the
Hartree-Fock (HF) level, the valence band binding energies are often estimated by simply taking the negative of the eigenenergies calculated for the neutral parent system (Koopmans' theorem); in the low binding energy region, it usually turns out that there occurs compensation between the relaxation and electron correlation effects, neither of which being taken into account explicitly in HF calculations. In contrast, since DFT calculations include estimates of electron correlation effects, the calculated orbital energies cannot be used directly to approximate binding energies, because of the lack of inclusion of relaxation effects. In the transition state model, the valence band binding energies are derived from the DFT eigenenergies obtained for the neutral molecule and for a partly ionized system. Within the GTS formalism, the binding energy of a given molecular orbital $k, I_{k}$, is given by

$$
I_{k}=\frac{1}{4}\left[\epsilon_{k}(1)+3 \epsilon_{k}(1 / 3)\right],
$$

where $\epsilon_{k}(n)$ is the eigenenergy of the molecular orbital $k$ with an electronic occupation of $n$. Thus, $\epsilon_{k}(1)$ and $\epsilon_{k}(1 / 3)$ are the $k$ orbital eigenenergies of the parent neutral system and of a partly ionized system corresponding to a removal of $2 / 3$ of one electron from the $k$ orbital in the $\alpha$ spin manifold (while leaving an occupation of 1 for the $k$ orbital in the $\beta$ spin manifold), respectively. ${ }^{28}$ This technique requires a series of additional self-consistent field (SCF) calculations, equal to the number of valence orbitals to be studied, to obtain the theoretical UPS spectrum. In the present work, we have applied the approximation of Duffy and Chong, ${ }^{30}$ wherein the partial electron removal is distributed over the whole set of valence molecular orbitals, allowing the determination of all of the valence band binding energies in a single computational run (in addition to the SCF calculations for the neutral system). This corresponds to the so-called diffuse ionization approximation; its use has been reported for a series of organic molecules and provides results that agree remarkably well with experimental data. ${ }^{30}$

\section{RESULTS AND DISCUSSION}

\section{A. Electronic structure of $\mathrm{Alq}_{3}$}

The ground-state electronic structure of $\mathrm{Alq}_{3}$ has been reported previously. ${ }^{31-33}$ Therefore, it is not discussed in detail here. Some aspects, however, are worth recalling in order to facilitate the discussions below. The topmost feature in the UPS valence spectrum of $\mathrm{Alq}_{3}$ corresponds to (nearly) triply degenerate orbitals, which originate in the highest occupied molecular orbital (HOMO) of each of the 8-quinolinol ligands. The $\mathrm{HOMO}$ in $\mathrm{Alq}_{3}$ is characterized by a strong localization to the phenoxide side of the ligands, whereas the LUMO is mainly localized on the pyridyl side. All $\pi$-type orbitals occur in groups of three, each ligand contributing one orbital; this means that, e.g., the LUMO-1 and LUMO-2 orbitals display a character similar to the LUMO, but are located on the other two ligands. Note that, to a first approximation, the characteristics of the LUMO can be taken to estimate where additional negative charges will be stored. 

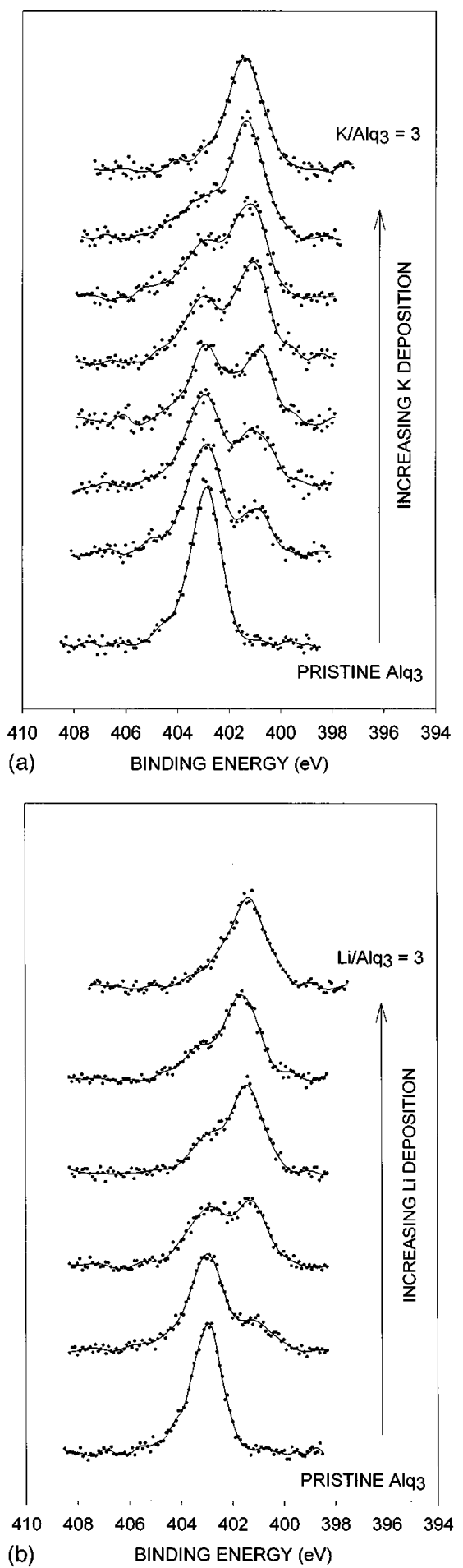

FIG. 2. Evolution of the N(1s) spectrum as a function of doping with (a) potassium and (b) lithium.

\section{B. Potassium and lithium doping}

Figure 2 illustrates the evolution of the XPS N( $1 s)$ spectrum in $\mathrm{Alq}_{3}$ as a function of deposition of potassium or lithium atoms. The lower curves correspond to the $\mathrm{N}(1 s)$ spectrum in pristine $\mathrm{Alq}_{3}$ films, while the upper curves correspond to a metal concentration of three metal atoms per $\mathrm{Alq}_{3}$ molecule. In pristine $\mathrm{Alq}_{3}$, the $\mathrm{N}(1 s)$ binding energy is $402.8 \mathrm{eV}( \pm 0.2 \mathrm{eV})$ relative to the vacuum level. Upon deposition of either lithium or potassium, a new spectral peak appears at lower binding energy in the $\mathrm{N}(1 s)$ spectrum, indicating that charge has been transferred from the metal atoms to the nitrogen atoms. In addition, the original $\mathrm{N}(1 s)$ peak gradually disappears during the course of metal deposition. The next-to-the-lowest curves correspond to an approximate metal concentration of one metal atom per $\mathrm{Alq}_{3}$ molecule. The relative intensity ratio of the higher to lower binding energy components is $2: 1$, indicating that the metal atoms, at this stage, donate charge to only one of the three ligands of the $\mathrm{Alq}_{3}$ molecules.

The continued increase in intensity of the new, lower binding energy $\mathrm{N}(1 s)$ peak with additional metal atom deposition is consistent with the fact that the subsequent electrons are not transferred to the same ligand to result in paired electrons; indeed, such a process would mean a more negative charge on that specific nitrogen atom, and, therefore an additional energy shift to even lower binding energies. The second electron thus obviously goes to one of the other two ligands. This is confirmed in the $\mathrm{N}(1 s)$ spectrum by the corresponding simultaneous decrease of the higher binding energy component. Eventually, at the level of three metal atoms per $\mathrm{Alq}_{3}$ molecule, each of the three different ligands has received one extra electron charge, resulting in just one corresponding peak in the $\mathrm{N}(1 s)$ spectrum. This analysis is in agreement with recently reported cyclic voltammetry data on a new sulfonamide derivative of $\mathrm{Alq}_{3}$, which shows three successive, chemically reversible, one-electron reductions, that are consistent with the reduction of each of the quinolate groups by one electron. ${ }^{34}$ Note that the position of the new lower binding energy peak is slightly different for each of the two metals; the new peak appears at $401.0 \mathrm{eV}$ for potassium deposition and $401.5 \mathrm{eV}$ for lithium deposition. This difference is in agreement with the higher ionization potential of lithium atoms vs potassium atoms, $5.39 \mathrm{eV}$ vs 4.34 $\mathrm{eV}^{35}$ as a consequence, less net charge is expected to be transferred from the lithium atoms to the $\mathrm{Alq}_{3}$ molecules than in the case of potassium doping, which results in a smaller shift of the peak in the $\mathrm{N}(1 s)$ spectrum for lithium deposition.

Figure 3 shows the evolution of the He I valence band spectrum, as well as a blow up of the low binding energy portion of the same spectrum, during potassium deposition (again, the lower spectrum corresponds to pristine $\mathrm{Alq}_{3}$, while the top spectrum corresponds to a metal concentration of three potassium atoms per $\mathrm{Alq}_{3}$ molecule). At low doping levels, one new peak appears within the original energy gap; this peak evolves uniformly in intensity, up to a doping level of three potassium atoms per $\mathrm{Alq}_{3}$ molecule. At all levels of doping, the new peak is separated from the peak that contains contributions from the original $\mathrm{HOMO}$ by $1.6 \mathrm{eV}$ and is located at $5.0 \mathrm{eV}$ below the vacuum level. The evolution in the valence band region is consistent with the evolution of the $\mathrm{N}(1 s)$ spectra and confirms that, up to a doping level of three electrons per $\mathrm{Alq}_{3}$ molecule, each of the electrons prefers to reside on separate ligands. Note especially that during the doping sequence the Fermi level is never coincident with the new peak. This is true despite the fact that, for example, at the doping level of one potassium/lithium atom per $\mathrm{Alq}_{3}$ 


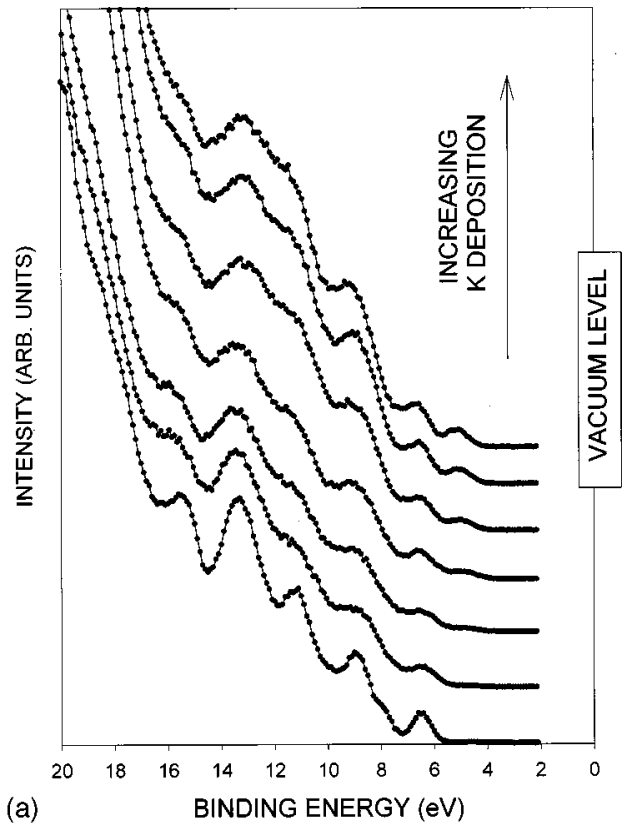

(a)

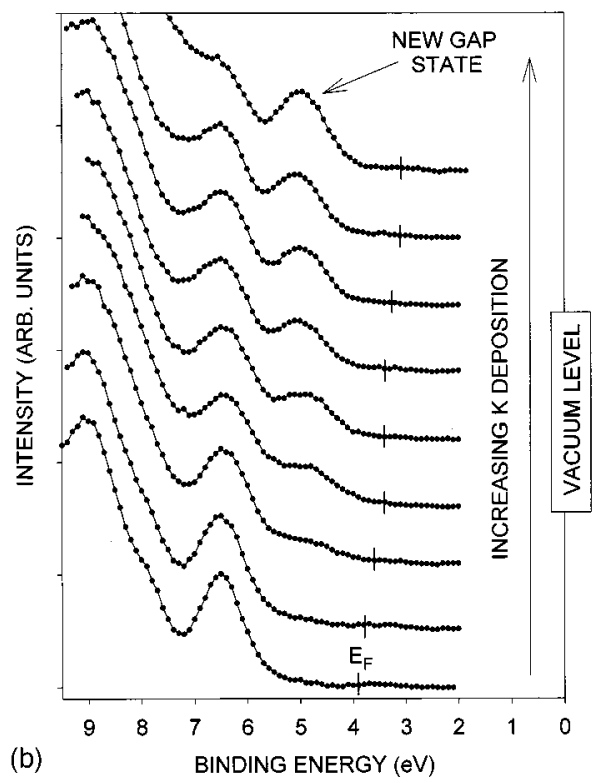

FIG. 3. Evolution of the full valence band spectrum as a function of potassium doping (a) and blow up of the uppermost part of the same spectrum (b).

molecule, the new gap state is singly occupied and that, at the doping level of three potassium/lithium atoms per $\mathrm{Alq}_{3}$ molecule, the three topmost orbitals are all singly occupied. Actually, in the latter situation, it is no longer relevant to discuss the electronic structure in the simple orbital picture, i.e., at the single particle level of theory. The electronic structure becomes here a result of electron correlation effects. These effects are important in the case of $\left(\mathrm{Alq}_{3}\right)^{3-}$, since the set of orbitals that becomes occupied upon doping shows almost no hybridization among the ligands and the excess electrons gain very little energy by delocalizing over the whole system; they remain therefore localized to a single ligand. Since the ligands are fairly small, there is a substantial Coulomb repulsion energy associated with putting a second charge on a single ligand. This repulsion thus leads to

\section{$\mathrm{Alq}_{3}$ Numbering}
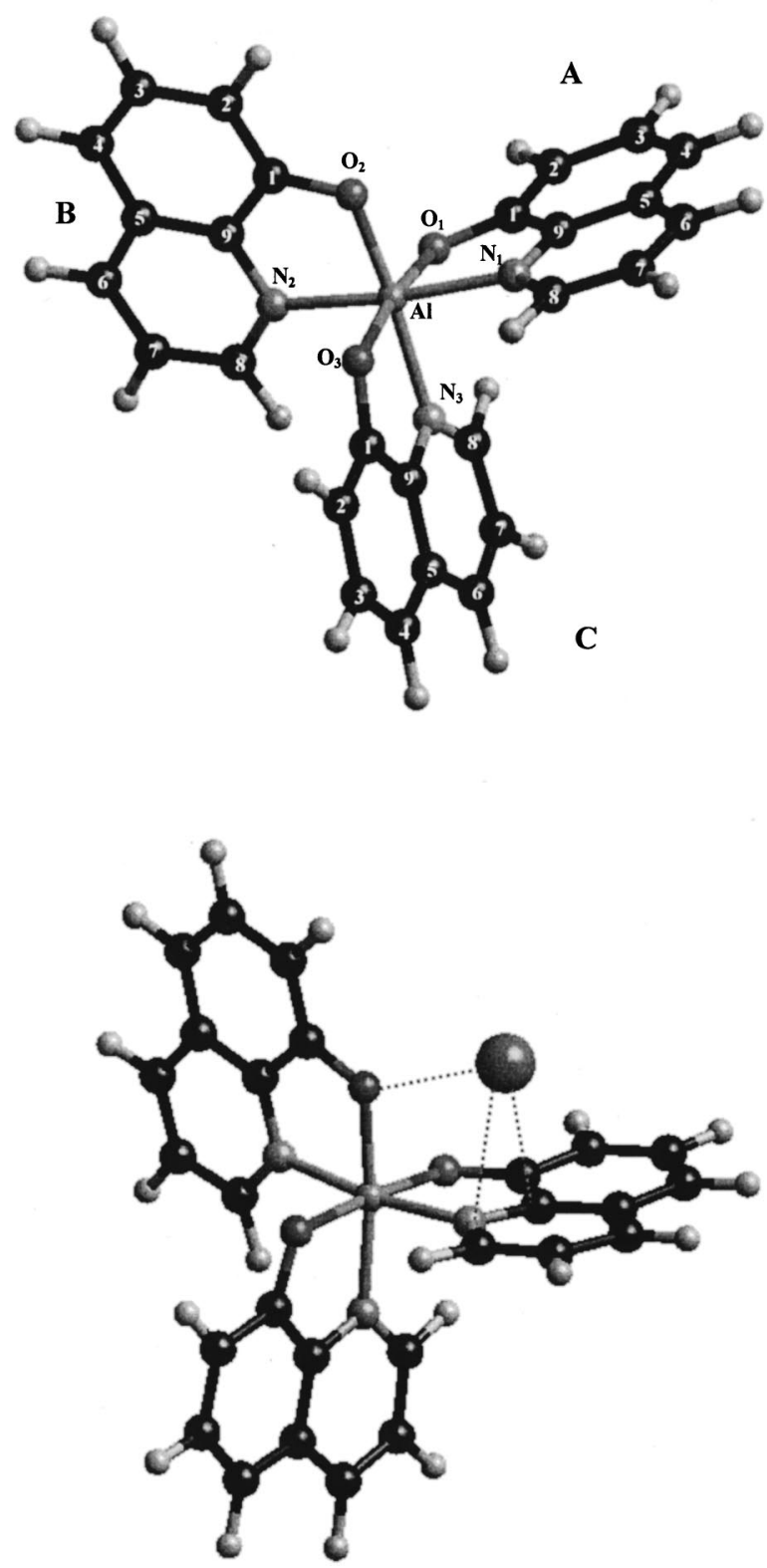

FIG. 4. Sketch of the DFT-LSDA optimized geometry of the $\mathrm{Alq}_{3}$ molecule (top) and of the $\mathrm{K} / \mathrm{Alq}_{3}$ complex (bottom). The atom and ligand labeling is shown in the top panel.

the situation in which the added electrons are localized to separate ligands; in a condensed-matter physics context, this situation corresponds to the opening of a Coulomb gap around the Fermi energy. This explains why in the experimental data of the $\mathrm{K}_{3} \mathrm{Alq}_{3}$ system, the Fermi energy lies about $2 \mathrm{eV}$ above the doping-induced peak. The evolution of the valence band spectrum as lithium atoms are deposited on the surface is found to be essentially identical to that for potassium deposition and is therefore not shown here.

Figure 4 illustrates the DFT optimized geometries of the $\mathrm{Alq}_{3}$ molecule (where the three ligands are labeled A, B, and C) and of the complex with one potassium atom. The results in Fig. 4 are presented for the meridianal isomer, which has 
TABLE I. DFT optimized bond lengths $(\AA)$ in $\mathrm{Alq}_{3}$ and the complex with one $\mathrm{K}$ atom. ${ }^{\mathrm{a}}$ The values in bold indicate the bonds that undergo the largest changes. A, B, and $\mathrm{C}$ refer to the three ligands, as labeled in Fig. 4. The table is divided into five sections; the first deals with the aluminum-ligand bonds; the following three sections deal with the ligands themselves; the last section deals with the new bonds formed between the $\mathrm{K}$ atom and the $\mathrm{Alq}_{3}$ molecule.

\begin{tabular}{|c|c|c|}
\hline Bonds & $\mathrm{Alq}_{3}$ & $\mathrm{Alq}_{3}+\mathrm{K}$ \\
\hline $\mathrm{Al}-\mathrm{O}_{1}(\mathrm{~A})$ & 1.868 & 1.866 \\
\hline $\mathrm{Al}-\mathrm{O}_{2}(\mathrm{~B})$ & 1.839 & 1.912 \\
\hline $\mathrm{Al}-\mathrm{O}_{3}(\mathrm{C})$ & 1.864 & 1.860 \\
\hline $\mathrm{Al}-\mathrm{N}_{1}(\mathrm{~A})$ & 2.019 & 1.963 \\
\hline $\mathrm{Al}-\mathrm{N}_{2}(\mathrm{~B})$ & 2.019 & 2.003 \\
\hline $\mathrm{Al}-\mathrm{N}_{3}(\mathrm{C})$ & 2.051 & 1.999 \\
\hline $\mathrm{O}_{1}-1(\mathrm{~A})$ & 1.310 & 1.319 \\
\hline $1-2(\mathrm{~A})$ & 1.388 & 1.398 \\
\hline $2-3(\mathrm{~A})$ & 1.402 & 1.395 \\
\hline $3-4(\mathrm{~A})$ & 1.379 & 1.389 \\
\hline $4-5$ (A) & 1.406 & 1.407 \\
\hline $5-6(\mathrm{~A})$ & 1.407 & 1.420 \\
\hline $5-9(\mathrm{~A})$ & 1.414 & 1.414 \\
\hline $6-7(\mathrm{~A})$ & 1.376 & 1.397 \\
\hline $7-8(\mathrm{~A})$ & 1.401 & 1.385 \\
\hline $8-\mathrm{N}_{1}(\mathrm{~A})$ & 1.322 & 1.357 \\
\hline $\mathrm{N}_{1}-9(\mathrm{~A})$ & 1.353 & 1.378 \\
\hline $9-1$ (A) & 1.424 & 1.416 \\
\hline $\mathrm{O}_{2}-1$ (B) & 1.306 & 1.319 \\
\hline 1-2 (B) & 1.390 & 1.387 \\
\hline $2-3(B)$ & 1.400 & 1.402 \\
\hline $3-4(B)$ & 1.380 & 1.377 \\
\hline $4-5(B)$ & 1.405 & 1.405 \\
\hline $5-6(B)$ & 1.405 & 1.407 \\
\hline $5-9$ (B) & 1.415 & 1.411 \\
\hline $6-7$ (B) & 1.375 & 1.376 \\
\hline $7-8$ (B) & 1.400 & 1.397 \\
\hline $8-\mathrm{N}_{2}(\mathrm{~B})$ & 1.321 & 1.323 \\
\hline $\mathrm{N}_{2}-9$ (B) & 1.354 & 1.352 \\
\hline $9-1$ (B) & 1.425 & 1.421 \\
\hline $\mathrm{O}_{3}-1(\mathrm{C})$ & 1.307 & 1.315 \\
\hline $1-2(\mathrm{C})$ & 1.390 & 1.390 \\
\hline $2-3(\mathrm{C})$ & 1.401 & 1.401 \\
\hline $3-4(\mathrm{C})$ & 1.379 & 1.381 \\
\hline $4-5(\mathrm{C})$ & 1.406 & 1.406 \\
\hline $5-6(C)$ & 1.407 & 1.410 \\
\hline $5-9(\mathrm{C})$ & 1.415 & 1.412 \\
\hline $6-7(\mathrm{C})$ & 1.377 & 1.380 \\
\hline $7-8(C)$ & 1.401 & 1.396 \\
\hline $8-\mathrm{N}_{3}(\mathrm{C})$ & 1.324 & 1.331 \\
\hline $\mathrm{N}_{3}-9(\mathrm{C})$ & 1.352 & 1.357 \\
\hline $9-1(\mathrm{C})$ & 1.423 & 1.421 \\
\hline $\mathrm{K}-\mathrm{Al}(\mathrm{A})$ & $\ldots$ & 3.483 \\
\hline $\mathrm{K}-\mathrm{O}_{1}(\mathrm{~A})$ & $\cdots$ & 3.563 \\
\hline $\mathrm{K}-\mathrm{O}_{2}(\mathrm{~B})$ & $\ldots$ & 2.496 \\
\hline $\mathrm{K}-\mathrm{N}_{1}(\mathrm{~A})$ & $\ldots$ & 2.709 \\
\hline $\mathrm{K}-1$ (A) & $\cdots$ & 3.176 \\
\hline $\mathrm{K}-9$ (A) & $\cdots$ & 2.711 \\
\hline $\mathrm{K}-8$ (A) & $\cdots$ & 3.118 \\
\hline
\end{tabular}

${ }^{a}$ The optimized DFT coordinates can be obtained from the authors by simple e-mail request to D. A. dos Santos: Doni@averell.umh.ac.be

the lowest ground-state energy $;^{33}$ this is the only isomer that has been observed in the crystalline state. ${ }^{36,37}$ As shown in Fig. $4, \mathrm{Alq}_{3}$ is an organometallic complex in which the metal atom has a distorted octahedral coordination; in the meridi-
TABLE II. Mulliken atomic charges (in $|e|$ ) in the $\mathrm{Alq}_{3}$ molecule and the complex with one potassium atom, as obtained from DFT calculations using the BLYP gradient-corrected exchange-correlation functional, with a DNP basis set.

\begin{tabular}{|c|c|c|c|}
\hline Atom & $\mathrm{Alq}_{3}$ & $\mathrm{Alq}_{3}+\mathrm{K}$ & $\Delta q$ \\
\hline $\mathrm{Al}$ & 0.805 & 0.798 & -0.007 \\
\hline $\mathrm{O}_{1}(\mathrm{~A})$ & -0.615 & -0.629 & -0.014 \\
\hline $\mathrm{O}_{2}(\mathrm{~B})$ & -0.587 & -0.675 & -0.088 \\
\hline $\mathrm{O}_{3}(\mathrm{C})$ & -0.594 & -0.615 & -0.021 \\
\hline $\mathrm{N}_{1}(\mathrm{~A})$ & -0.331 & -0.473 & -0.142 \\
\hline $\mathrm{N}_{2}$ (B) & -0.327 & -0.321 & 0.006 \\
\hline $\mathrm{N}_{3}(\mathrm{C})$ & -0.367 & -0.392 & -0.025 \\
\hline 1 (A) & 0.256 & 0.228 & -0.028 \\
\hline $2(\mathrm{~A})$ & -0.296 & -0.324 & -0.028 \\
\hline $3(\mathrm{~A})$ & -0.224 & -0.259 & -0.035 \\
\hline $4(\mathrm{~A})$ & -0.272 & -0.275 & -0.003 \\
\hline $5(\mathrm{~A})$ & -0.011 & -0.065 & -0.054 \\
\hline $6(\mathrm{~A})$ & -0.211 & -0.279 & -0.068 \\
\hline $7(\mathrm{~A})$ & -0.289 & -0.326 & -0.037 \\
\hline $8(\mathrm{~A})$ & -0.065 & -0.128 & -0.063 \\
\hline $9(\mathrm{~A})$ & 0.208 & 0.097 & -0.111 \\
\hline 1 (B) & 0.272 & 0.257 & -0.015 \\
\hline 2 (B) & -0.293 & -0.281 & 0.012 \\
\hline $3(\mathrm{~B})$ & -0.229 & -0.234 & -0.005 \\
\hline 4 (B) & -0.266 & -0.262 & 0.004 \\
\hline $5(\mathrm{~B})$ & -0.006 & -0.015 & -0.009 \\
\hline 6 (B) & -0.210 & -0.209 & 0.001 \\
\hline 7 (B) & -0.293 & -0.284 & 0.009 \\
\hline 8 (B) & -0.034 & -0.027 & 0.007 \\
\hline 9 (B) & 0.197 & 0.201 & 0.004 \\
\hline $1(\mathrm{C})$ & 0.249 & 0.249 & 0.000 \\
\hline $2(\mathrm{C})$ & -0.306 & -0.315 & -0.009 \\
\hline $3(\mathrm{C})$ & -0.214 & -0.229 & -0.015 \\
\hline $4(\mathrm{C})$ & -0.271 & -0.275 & -0.004 \\
\hline $5(\mathrm{C})$ & -0.010 & -0.008 & 0.002 \\
\hline $6(\mathrm{C})$ & -0.214 & -0.212 & 0.002 \\
\hline 7 (C) & -0.298 & -0.285 & 0.013 \\
\hline $8(\mathrm{C})$ & -0.081 & -0.083 & -0.002 \\
\hline $9(\mathrm{C})$ & 0.188 & 0.192 & 0.004 \\
\hline K & 0 & 0.866 & 0.866 \\
\hline
\end{tabular}

anal isomer, only one oxygen has a nitrogen atom located at the opposite position, in contrast to the facial $\mathrm{Alq}_{3}$ geometrical isomer (illustrated in Fig. 1), in which the three oxygens and the three nitrogens are located on the opposite vertices of the distorted octahedron.

The potassium atom interacts mainly with one of the ligands (A), but also to a lesser degree with the oxygen atom of another ligand (B). In fact, a detailed analysis of the molecular orbitals of the $\mathrm{K} / \mathrm{Alq}_{3}$ complex indicates that a specific interaction takes place between the $\mathrm{K}$ atom and a lone pair of the oxygen atom in ligand B. This interaction leads to a stabilization by $\approx 0.6 \mathrm{eV}$ of the molecular orbital built from this oxygen atom lone pair with respect to the corresponding molecular orbital in pristine $\mathrm{Alq}_{3}$. This aspect of the $\mathrm{Alq}_{3}$ doping is in agreement with the voltammetric behavior of the sulfonamide derivative of $\mathrm{Alq}_{3},{ }^{34}$ characterized by three successive reduction processes; the spacing between the waves was suggested to be an indication of the fact that the reduction of the first quinolate affects the reduction potential of the successive electron-transfer events. Table I 


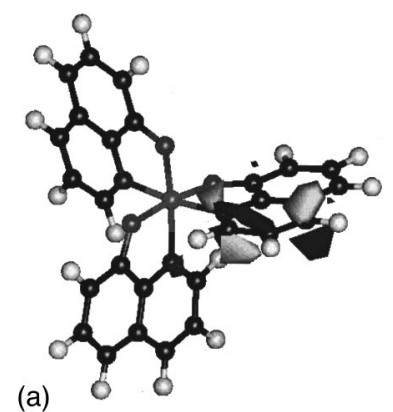

\section{LUMO of Pristine $\mathrm{Alq}_{3}$}

(b)

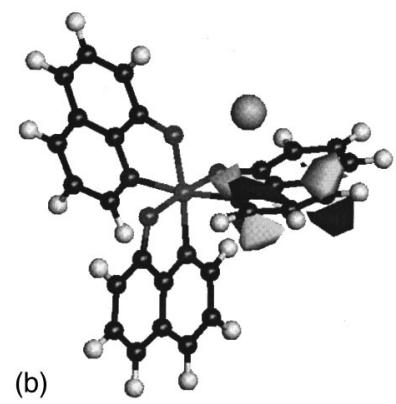

SOMO of $\mathrm{K}$ doped $\mathrm{Alq}_{3}$

FIG. 5. Sketch of pristine $\mathrm{Alq}_{3} \mathrm{LUMO}$ and of potassium-doped $\mathrm{Alq}_{3} \mathrm{SOMO}$ as calculated at the BLYP gradient-corrected DFT level.

shows the calculated bond lengths of pristine $\mathrm{Alq}_{3}$ as well as those in its complex with one potassium atom. The three shortest bonds involving the potassium atom are in increasing order, to the oxygen atom of ligand $\mathrm{B}(2.50 \AA)$, to the nitrogen atom of ligand $\mathrm{A}(2.71 \AA)$, and to carbon atom number 9 of ligand A $(2.71 \AA)$. The complexation with one potassium atom also results in fairly large changes in three of the six aluminum-ligand bond lengths, i.e., the aluminum to oxygen bond in ligand $\mathrm{B}$ and the two aluminum to nitrogen bonds in ligands $\mathrm{A}$ and $\mathrm{C}$. Within the ligands, the bonds in the vicinity of the nitrogen atom in ligand A experience the largest changes in length; the bonds in ligands $\mathrm{B}$ and $\mathrm{C}$ are hardly affected at all. Table II illustrates the Mulliken atomic charges in the $\mathrm{Alq}_{3}$ molecule and its complex with potassium. The potassium atom is calculated to lose about 0.866 $|e|$; most of this charge is transferred to ligand $\mathrm{A}(0.63|e|)$, whereas ligands $\mathrm{B}$ and $\mathrm{C}$ are calculated to share nearly equivalent parts of the rest of the transferred charge $(\approx 0.11$ $|e|$ each). Within the ligands, the nitrogen atom in ligand $\mathrm{A}$ receives the largest amount of negative charge $(0.142|e|)$; the oxygen atom in ligand $\mathrm{B}$ as well as some of the carbon atoms in ligand $\mathrm{A}$ also receive some significant negative charge. These calculated charge transfers are fully consistent with what is expected from inspection of the LUMO wave function of the $\mathrm{Alq}_{3}$ molecule; the largest changes are observed for the pyridyl side of the ligand, where the LUMO is mainly located. This is clearly seen in Fig. 5, where the new singly occupied $\mathrm{MO}(\mathrm{SOMO})$ of potassium-doped $\mathrm{Alq}_{3}$ is shown to be almost identical to the original LUMO of $\mathrm{Alq}_{3}$.

Figure 6 shows a comparison of the top (lowest binding energy) portion of the valence region, where the experimental and theoretical density-of-valence-states (DOVS) are compared, both for a doping level corresponding to one potassium atom per $\mathrm{Alq}_{3}$ molecule. It can be seen that there is

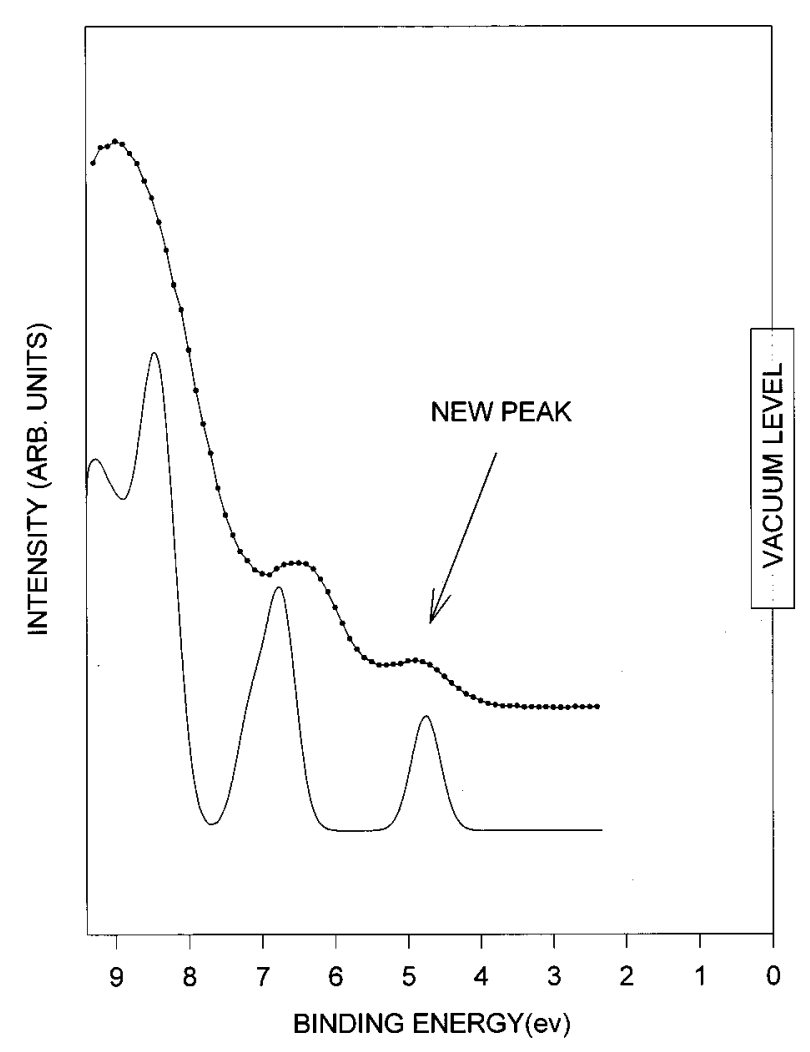

FIG. 6. Comparison between the experimental (UPS He I) DOVS (upper curve) and the theoretical DOVS (lower curve), obtained from a generalized transition state calculation on the basis of the DFT formalism, corresponding to a doping level of one potassium atom per $\mathrm{Alq}_{3}$ molecule.

an excellent agreement between experiment and theory. The theoretical calculation predicts a slightly larger splitting (about $1.9 \mathrm{eV}$ ), between the new state in the original forbidden energy gap and the peak corresponding to the old HOMO, than what is measured experimentally (about 1.6 $\mathrm{eV})$. This difference can, at least partly, be attributed to the fact that the calculation is performed in the "gas phase" with no polarizing medium surrounding $\mathrm{Alq}_{3}$. Therefore, in the calculation, the extra electron that is added to the system is more strongly repelled by the other electrons in the molecule than in the real material where this repulsion is reduced by screening due to electrons on neighboring molecules. Inspection of the wave functions indicates that the new peak corresponds to the LUMO of pristine $\mathrm{Alq}_{3}$, and that the previous HOMO has become HOMO-1. Additional discussions of the modeling, corresponding to higher doping levels, are not necessary, since the evolution of both the $\mathrm{N}(1 s)$ spectrum and the UPS spectrum is consistent with the notion that the subsequent two potassium atoms react with the two remaining ligands, up to a doping level corresponding to three potassium atoms per $\mathrm{Alq}_{3}$ molecule. Thus, upon charge transfer doping, the $\mathrm{Alq}_{3}$ molecule behaves as if the three ligands were nearly independent of each other.

A final important point is that, according to angledependent XPS data, the K-atoms are uniformly distributed throughout the near surface region of the condensed molecular films, that is, within the depths accessible to XPS, on the order of $50-100 \AA$. 


\section{SYNOPSIS}

The electronic structure of $\mathrm{Alq}_{3}$ has been investigated in the reduced state following in situ deposition of lithium or potassium atoms onto ultrathin films of the condensed molecular solid. Both $\mathrm{K}$ and $\mathrm{Li}$ atoms are found to donate electrons to the $\mathrm{Alq}_{3}$ molecule. The results indicate differences between the two metals, associated with the differences in chemical reactivity; potassium atoms donate slightly more charge than lithium atoms to $\mathrm{Alq}_{3}$ molecules. Both the experimental spectra and the theoretical modeling show that at a doping level of one potassium atom per $\mathrm{Alq}_{3}$ molecule, the potassium atom interacts mainly with one of the ligands; in addition, there is a weaker interaction with a lone pair of one of the oxygen atoms of a neighboring ligand. In the presence of the counterions, each $\mathrm{Alq}_{3}$ molecule accepts one electron per ligand, up to three electrons per molecule. Coulomb repulsion prevents placing a second electron on a ligand that already contains one excess electron, which leads to a Coulomb gap around the Fermi energy in the electronic structure.

\section{ACKNOWLEDGMENTS}

The work in Linköping was supported by Sumitomo Chemicals Co., Japan. Research on condensed molecular solids and conjugated polymers in Linköping is supported in general by grants from the Swedish Natural Sciences Research Council (NFR), the Swedish Research Council for Engineering Sciences (TFR), and the Carl Tryggers Foundation. The Linköping-Mons collaboration is conducted within the European Commission Training and Mobility of Researchers (TMR) Network on "Synthetic Electroactive Organic Architectures (SELOA).' The work in Mons is partly supported by the Belgian Federal Government "InterUniversity Attraction Pole on Supramolecular Chemistry and Catalysis (PAI 4/11)" and FNRS-FRFC.

${ }^{1}$ C. W. Tang and S. Av. Slyke, Appl. Phys. Lett. 51, 913 (1987).

${ }^{2}$ K. M. Vaeth and K. F. Jensen, Appl. Phys. Lett. 71, 2091 (1997).

${ }^{3}$ C. W. Tang, S. A. v. Slyke, and C. H. Chen, J. Appl. Phys. 65, 3610 (1989).

${ }^{4}$ G. Gu, V. Bulovic, P. E. Burrows, S. R. Forrest, and M. E. Thompson, Appl. Phys. Lett. 68, 2606 (1996).

${ }^{5}$ P. E. Burrows, V. Bulovic, S. R. Forrest, L. S. Sapochak, D. M. McCarty, and M. E. Thompson, Appl. Phys. Lett. 65, 2922 (1994).

${ }^{6}$ C. C. Wu, J. K. M. Chun, P. E. Burrows, J. C. Sturm, M. E. Thompson, S. R. Forrest, and R. A. Register, Appl. Phys. Lett. 66, 653 (1995).

${ }^{7}$ P. Dannetun, M. Lögdlund, J. L. Brédas, C. W. Spangler, and W. R. Salaneck, J. Phys. Chem. 98, 2853 (1994).

${ }^{8}$ M. Fahlman, D. Beljonne, M. Lögdlund, R. H. Friend, A. B. Holmes, J. L. Brédas, and W. R. Salaneck, Chem. Phys. Lett. 214, 327 (1993).
${ }^{9}$ M. Fahlman, M. Lögdlund, S. Stafström, W. R. Salaneck, R. H. Friend, P. L. Burn, A. B. Holmes, K. Kaeriyama, Y. Sonoda, O. Lhost, F. Meyers, and J. L. Brédas, Macromolecules 28, 1959 (1995).

${ }^{10}$ M. Lögdlund, P. Dannetun, and W. R. Salaneck, in Handbook of Conducting Polymers, 2nd ed., edited by T. A. Skotheim, R. L. Elsenbaumer, and J. R. Reynolds (Marcel Dekker, New York, 1998).

${ }^{11}$ K. Z. Xing, M. Fahlman, M. Berggren, O. Inganäs, M. R. Andersson, M. Boman, S. Stafström, G. Iucci, P. Bröms, N. Johansson, M. Lögdlund, and W. R. Salaneck, Synth. Met. 76, 263 (1996).

${ }^{12}$ K. Z. Xing, M. Fahlman, M. Lögdlund, M. Berggren, O. Inganäs, M. R. Andersson, M. Bohman, S. Stafström, G. Iucci, P. Bröms, N. Johansson, and W. R. Salaneck, Synth. Met. 80, 59 (1996).

${ }^{13}$ G. Iucci, K. Xing, M. Lögdlund, M. Fahlman, and W. R. Salaneck, Chem. Phys. Lett. 244, 139 (1995).

${ }^{14}$ W. R. Salaneck, S. Stafström, and J. L. Brédas, Conjugated Polymer Surfaces and Interfaces (Cambridge University Press, Cambridge, 1996).

${ }^{15}$ R. G. Parr and W. Yang, Density Functional Theory of Atoms and Molecules (Oxford University Press, New York, 1989).

${ }^{16}$ C. Fredriksson and S. Stafström, J. Chem. Phys. 101, 9137 (1994).

${ }^{17}$ C. Fredriksson, R. Lazzaroni, J. L. Brédas, P. Dannetun, M. Lögdlund, and W. R. Salaneck, Synth. Met. 55-57, 4632 (1993).

${ }^{18}$ C. Fredriksson, R. Lazzaroni, J. L. Brédas, A. Ouhlal, and A. Selmani, J. Chem. Phys. 100, 9258 (1994).

${ }^{19}$ V. Parente, C. Fredriksson, A. Selmani, R. Lazzaroni, and J. L. Brédas, J. Phys. Chem. B 101, 4193 (1997).

${ }^{20}$ V. Parente, G. Pourtois, R. Lazzaroni, J. L. Brédas, G. Ruani, M. Murgia, and R. Zamboni, Adv. Mater. 3, 319 (1998).

${ }^{21}$ C. S. Fadley, in Electron Spectroscopy: Theory, Techniques, and Applications, edited by C. R. Brundle and A. D. Baker (Academic, London, 1978).

${ }^{22}$ B. Delley, J. Chem. Phys. 94, 7245 (1991).

${ }^{23}$ B. Delley, J. Chem. Phys. 92, 508 (1990).

${ }^{24}$ S. M. Vosko, L. Wilk, and M. Nusair, Can. J. Phys. 58, 1200 (1980).

${ }^{25}$ DMol, DMol User Guide (Molecular Simulations, San Diego, 1996).

${ }^{26}$ C. Lee, W. Yang, and R. G. Parr, Phys. Rev. B 38, 785 (1988).

${ }^{27}$ A. D. Becke, Phys. Rev. A 38, 3098 (1988).

${ }^{28}$ A. R. Williams, R. A. d. Groot, and C. B. Sommers, J. Chem. Phys. 63, 628 (1975).

${ }^{29}$ J. C. Slater, Adv. Quantum Chem. 6, 1 (1972).

${ }^{30}$ P. Duffy and D. P. Chong, Org. Mass Spectrom. 28, 321 (1993).

${ }^{31}$ K. Sugiyama, D. Yoshimura, E. Ito, T. Miyazaki, Y. Hamatani, I. Kawamoto, Y. Ouchi, and K. Seki, Mol. Cryst. Liq. Cryst. 285, 561 (1996).

${ }^{32}$ H. Ishii, D. Yoshimura, K. Sugiyama, S. Narioka, Y. Hamatani, I. Kawamoto, T. Miyazaki, Y. Ouchi, and K. Seki, Synth. Met. 85, 1389 (1997).

${ }^{33}$ A. Curioni, W. Andreoni, R. Treusch, F. J. Himpsel, E. Haskal, P. Seidler, C. Heske, S. Kakar, T. v. Buuren, and L. J. Terminello, Appl. Phys. Lett. 72, 1575 (1998).

${ }^{34}$ J. D. Anderson, E. M. McDonald, M. L. A. P. A. Lee, E. L. Ritchie, H. K. Hall, T. Hopkins, E. A. Mash, J. Wang, A. Padias, S. Thayumanavan, S. Barlow, S. R. Marder, G. E. Jabbour, S. Shaheen, B. Kippelen, N. Peyghambarian, R. M. Wightman, and N. R. Armstrong, J. Am. Chem. Soc. 120, 9646 (1998).

${ }^{35}$ Handbook of Chemistry and Physics, 65th ed., edited by R. C. Weast (Chemical Rubber, Boca Raton, 1984).

${ }^{36}$ I. Fujii, N. Hirayama, J. Ohtani, and K. Kodama, Anal. Sci. 12, 153 (1996).

${ }^{37}$ H. Schmidbauer, J. Lettenbauer, D. L. Wilkinsson, G. Muller, and O. Kumberger, Z. Naturforsch. B 46, 1766 (1991). 